\title{
Exceptional response to everolimus in a novel tuberous sclerosis complex-2 mutation-associated metastatic renal-cell carcinoma
}

\author{
Samer Alsidawi ${ }^{1}$ and Pashtoon Murtaza Kasi ${ }^{2}$ \\ 'Division of Hematology/Oncology, Mayo Clinic, Rochester, Minnesota 55905, USA; ${ }^{2}$ Division of Hematology/ \\ Oncology, Mayo Clinic, Jacksonville, Florida 32224, USA
}

\begin{abstract}
Everolimus, an oral inhibitor of the mammalian target of rapamycin (mTOR) pathway, is currently approved for treatment of advanced renal-cell carcinoma (RCC) after failure of initial treatment with the tyrosine kinase inhibitors. Patients with tuberous sclerosis complex (TSC) syndrome can also develop RCC primarily mediated through mTOR signaling. However, the efficacy and duration of response of mTOR inhibition in patients with TSC-associated RCC is not well known. Herein, we describe a case of a patient with TSC2-associated metastatic RCC with mutations H1620R and Y1650C who has had an exceptional response to everolimus in the frontline setting and continues to derive benefit from mTOR inhibition 2 yr into therapy. Furthermore, the alteration H1620R in exon 37 resulting in a missense mutation is likely deleterious given our findings and previous analyses of the TSC2 gene. Further studies of somatic mutations in extended responders to mTOR inhibitors will help personalize therapy for these patients. It also emphasizes the value of targeted therapies based on genomic analyses.
\end{abstract}

Corresponding author: kasi.pashtoon@mayo.edu

(C) 2018 Alsidawi and Kasi This article is distributed under the terms of the Creative Commons Attribution-NonCommercial

License, which permits reuse and redistribution, except for commercial purposes, provided that the original author and source are credited.

Ontology terms: astrocytoma; clear cell renal cell carcinoma; generalized clonic seizures; malignant genitourinary tract tumor; papillary renal cell carcinoma type 1; papillary renal cell carcinoma type 2

Published by Cold Spring Harbor Laboratory Press

doi: $10.1101 / \mathrm{mcs} . \mathrm{a} 002220$
Tuberous sclerosis complex (TSC) is an autosomal dominant genetic disorder with multiorgan involvement affecting the brain, skin, heart, lungs, liver, and kidneys (Curatolo and Bombardieri 2007). Diagnosis is usually made based on clinical findings and family history. Genetic testing to confirm the diagnosis is not universally needed. TSC is caused by mutations in either the TSC1 (hamartin) gene on Chromosome 9 or the TSC2 (tuberin) gene on Chromosome 16 (Carbonara et al. 1994; Au et al. 1999; Kobayashi et al. 2001). This tumor-suppressing function of the TSC genes is mostly related to inhibition of cellular signaling and growth mediated by the mammalian target of rapamycin (mTOR) pathway (Tee et al. 2002). This is supported by the clinical phenotype in patients with TSC whereby they can develop numerous benign and malignant tumors in different organ systems. For example, patients with TSC can develop subependymal giant cell astrocytoma (SEGA) in the brain and angiomyolipomas in the kidneys. Additionally, patients with TSC syndrome are at increased risk of developing renal-cell carcinomas (RCCs) (Bjornsson et al. 1996; Henske 2004; Rakowski et al. 2006).

Everolimus, an oral inhibitor of the mTOR pathway, is currently approved for treatment of advanced RCC after failure of initial treatment with the tyrosine kinase inhibitors. It is not yet approved for treatment of RCC in the frontline setting. Additionally, the drug is approved for a number of indications in patients with TSC syndrome. In adults it is approved for patients with TSC syndrome and renal angiomyolipomas; and in both children and adults with TSC 
COLD SPRING HARBOR Molecular Case Studies
Tuberous sclerosis complex-associated renal cancer

syndrome who develop SEGA. In patients with TSC-associated RCC, the efficacy and duration of response are not known. Herein we describe a case of a patient with TSC-associated metastatic RCC who has had an exceptional response to everolimus in the frontline setting and continues to derive benefit from mTOR inhibition $2 \mathrm{yr}$ into therapy.

\section{CLINICAL PRESENTATION AND FAMILY HISTORY}

A 47-yr-old Caucasian male with a past medical history only significant for infantile seizures before age 5 presented to the emergency department with gross hematuria. Physical exam was significant for multiple hypomelanotic cutaneous lesions mostly noted on the back and the lower extremities. Additionally, multiple facial cutaneous lesions most consistent with facial angiofibromas were noted. Of note, the patient's mother was clinically diagnosed with TSC. She was reported to have classic skin findings, angiofibromas, brain tubers and, bilateral clear cell RCC at age 48. The patient's brother was also diagnosed with TSC at age 35 based on classical skin findings and brain tubers. The patient's nephew, son of the affected brother, had seizures, autism, and skin abnormalities consistent with TSC.

Because of the patient's significant hematuria, computed tomography (CT) of the abdomen was performed and showed multifocal bilateral renal masses suspicious of a malignant process with associated para-aortic lymphadenopathy. CT of the chest demonstrated numerous subcentimeter pulmonary nodules with a pattern most consistent with metastatic disease. These findings and family history raised the suspicion for TSC, and MRI of the brain with and without gadolinium was also performed and showed numerous nonspecific FLAIR/ T2 hyperintense lesions involving the cerebral hemispheres bilaterally with predominant involvement of the cortical gray matter without associated vasogenic edema, enhancement, or restricted diffusion most consistent with TSC. Figure 1 summarizes the spectrum of findings involving different organ systems noted in our patient.

The patient underwent a needle biopsy of one of the renal masses and pathology showed RCC with mixed papillary and clear cell features. The patient was evaluated by a medical geneticist who, based on clinical criteria and family history, diagnosed the patient with TSC. No confirmatory genetic testing was felt necessary. Tissue from the renal mass biopsy, however, was sent for genetic testing and that confirmed two TSC2 gene mutations (H1620R, Y1650C) alongside other aberrations as noted in Tables 1 and 2. These aberrations were reported out as variants of unknown significance. We did not find any previous reports of these two mutations. There is one report similar to the H1620R as a missense alteration that has been previously reported (Au et al. 1998). However, in that particular report, the amino acid reported is asparagine and not histidine, as in our report. Analysis of the TSC2 gene by $\mathrm{Au}$ and colleagues in 90 TSC patients did notice this alteration (DNA sequence change: 4859ArT; Codon change: Asn1620lle; Exon 37). This H1620R is likely another deleterious mutation. We did not find any previous reports of the TSC2 Y1650C alteration and this likely represents a variant of unknown significance (VUS) unless other reports or detailed family germline analyses corroborate these findings.

\section{CLINICAL COURSE AND MANAGEMENT}

Given the unique pathogenesis of RCC in TSC and the important dominant role of mTOR signaling, the patient was started on personalized off-label therapy with an mTOR inhibitor, everolimus, at a dose of $10 \mathrm{mg}$ oral on a daily basis in the frontline setting. The patient has tolerated the treatment well with no untoward side effects other than grade-1 stomatitis, hyperglycemia, and hypertriglyceridemia, which were managed conservatively without any 

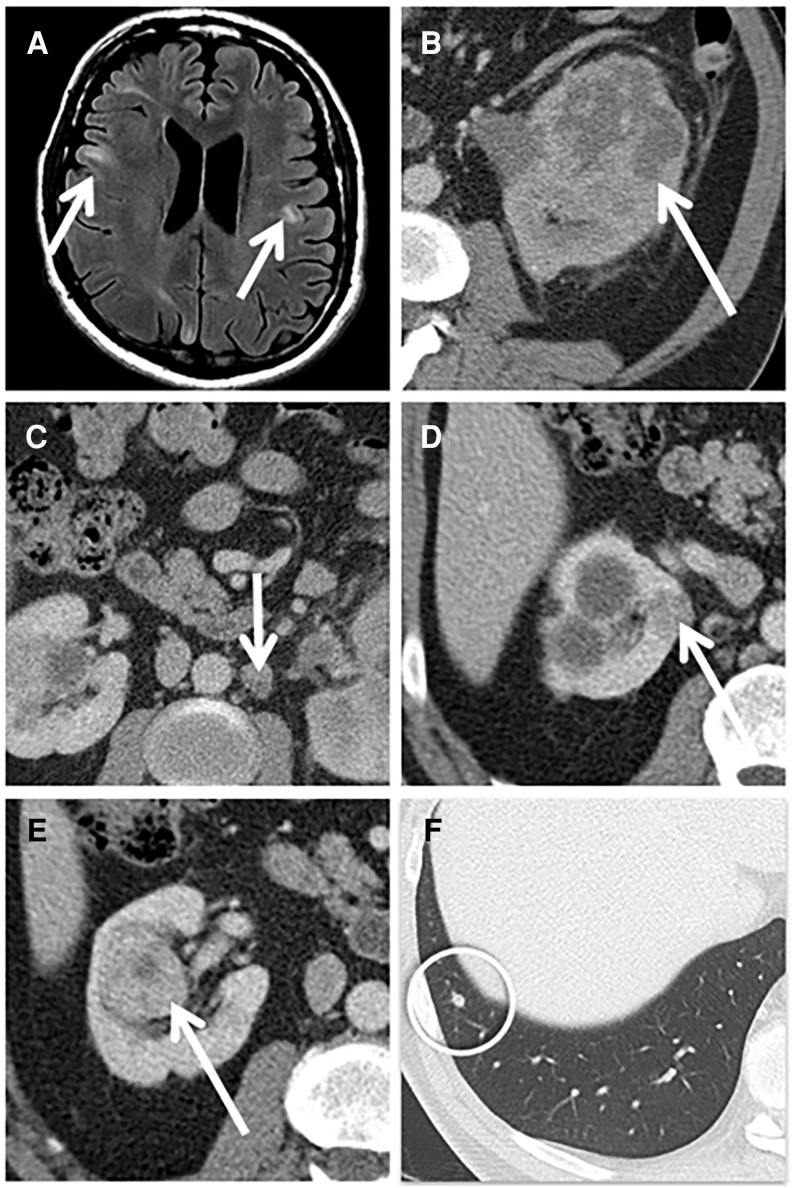

Figure 1. The spectrum of manifestations seen in our patient with tuberous sclerosis (TSC)-associated renalcell cancer. (A) MRI of the brain with gadolinium contrast showing numerous nonspecific FLAIR/T2 hyperintense lesions involving the cerebral hemispheres bilaterally with predominant involvement of the cortical gray matter without associated vasogenic edema, enhancement, or restricted diffusion consistent with TSC; (B) CT scan of the abdomen showing RCC forming multiple masses in the left kidney; (C) metastatic para-aortic adenopathy alongside cysts seen in the right kidney; $(D)$ angiomyolipomas seen in the right kidney alongside several cysts; $(E)$ angiomyolipoma seen in the right kidney; and $(F)$ subcentimeter nodules seen in the lung consistent with metastases from RCC.

Table 1. Commercial next-generation sequencing (NGS)-based assay identifying multiple genomic alterations alongside a brief description of potential personalized targeted therapies

\begin{tabular}{ll}
\hline Genomic alterations detected $^{a}$ & Potential targeted therapy \\
\hline TSC2 H1620R,Y1650C & Mammalian target of rapamycin (mTOR) inhibitors. \\
CDKN2A/B loss & Cyclin-dependent kinase (CDK) 4/6 inhibitors; \\
ARID2 L202 & mouse double minute 2 homolog (MDM2) inhibitors. \\
\hline
\end{tabular}

${ }^{\mathrm{a}}$ Other variants of unknown significance that were also detected on NGS assay (FoundationONE) included ARID1B Q129_Q130insQQ; BRCA2 D820G; DICER1 T1214P; FLT3 V5791; MAP3K1 S939C; RANBP2 K1479E; RICTOR rearrangement. 
Table 2. Details on TSC variants identified on NGS assay

\begin{tabular}{|c|c|c|c|c|c|c|c|c|c|}
\hline Gene & $\begin{array}{c}\text { Chromosome } \\
\text { position } \\
\text { (GRCh37) }\end{array}$ & HGVS cDNA & HGVS protein & Type & Effect & dbSNP ID & Genotype & $\begin{array}{c}\text { ClinVar } \\
\text { (number of } \\
\text { variants) }\end{array}$ & $\begin{array}{c}\text { Allele } \\
\text { Freq. } \\
\text { ExAC/ } \\
\text { gnomAD } \\
\text { (all) }\end{array}$ \\
\hline TSC2 (H1620R) & $\begin{array}{l}\text { NC_000016.10: } \\
\text { g.2086741A } \\
>\mathrm{G}\end{array}$ & $\begin{array}{c}\text { NM_000548.4: } \\
\text { c. } 4859 A>G\end{array}$ & $\begin{array}{l}\text { NP_000539.2: } \\
\text { p.His1620Arg }\end{array}$ & $\begin{array}{l}\text { Single-nucleotide } \\
\text { variant }\end{array}$ & Missense & 397515177 & Not known & $\begin{array}{l}\text { Uncertain } \\
\text { significance }\end{array}$ & $N R^{a}$ \\
\hline TSC2 (Y1650C) & $\begin{array}{c}\text { NC_000016.10: } \\
\text { g.2086831A } \\
\text { >G (GRCh38) }\end{array}$ & $\begin{array}{c}\text { NM_000548.4: } \\
\text { c. } 4949 A>G\end{array}$ & $\begin{array}{l}\text { NP_000539.2: } \\
\text { p.Tyr1650Cys }\end{array}$ & $\begin{array}{l}\text { Single-nucleotide } \\
\text { variant }\end{array}$ & Missense & 45501091 & Not known & $\begin{array}{l}\text { Uncertain } \\
\text { significance }\end{array}$ & $N R^{a}$ \\
\hline
\end{tabular}

TSC, tuberous sclerosis complex; NGS, next-generation sequencing; HGVS, Human Genome Variation Society; dbSNP, Database for Short Genetic Variations; NR, not reported.

aAllele frequencies (Allele freq.) were taken from Exome Aggregation Consortium (ExAC; http://exac.broadinstitute.org).

dose reductions or interruptions. Repeat CT scans approximately every 3 mo have shown excellent response in most disease sites and stable disease in the rest. Figure 2 shows the dramatic response in one of the main renal lesions alongside shrinkage noted in the associated para-aortic adenopathy 3- and 6-mo into therapy with everolimus.

\section{DISCUSSION}

Renal involvement in TSC is very common and is seen in $>80 \%$ of patients and this includes angiomyolipomas, cysts, and RCC (Fig. 1; Kwiatkowski et al. 2011). Complications from renal disease are in fact the leading cause of death in TSC (Shepherd et al. 1991). The incidence of RCC in TSC is not very well documented in the literature but is estimated to be $2 \%-4 \%$ in some reports (Lipworth et al. 2006). TSC-associated RCC are thought to be a distinct pathological entity. To further classify the pathology of RCC in TSC, Yang et al. (2014) studied 46 renal tumors in a series of 19 patients and classified them into three groups based on histopathology. The most common subtype had a distinct prominent papillary architecture similar to findings in our patient.

RCC in the general population is usually diagnosed in the sixth to eighth decade of life with a median age at diagnosis of $64 \mathrm{yr}$ (Siegel et al. 2015). Bilateral RCC and RCC diagnosed at a younger age should always raise the suspicion for hereditary kidney cancer syndromes. A careful personal and family history is of utmost importance. Although our patient had a strong family history of TSC, it is important to note that $80 \%$ of TSC cases are caused by de novo mutations (mostly in the TSC2 gene) (Au et al. 2007).

Robust evidence exists to suggest abnormal activation of the mTOR pathway and its downstream mediators in benign and malignant tumors in TSC (El-Hashemite et al. 2003; Kwiatkowski and Manning 2014). This has been successfully exploited in the EXIST-1 trial where 117 TSC patients with SEGAs were randomized to everolimus or placebo (Franz et al. 2013). Additionally, mTOR inhibitors are FDA-approved drugs used in the treatment of advanced RCC in the first- and second-line settings (Hudes et al. 2007; Motzer et al. 2010). Very few reports in the literature have explored the efficacy of mTOR inhibitors in TSC-associated RCC (Pressey et al. 2010; Kim et al. 2014). Although mTOR inhibitors remain FDA-approved for metastatic RCC in the first- and second-line settings, recent advances in the treatment of RCC have led to a justified decreased interest in the use of mTOR inhibitors as they showed less activity compared to more recently discovered anti-angiogenic agents 

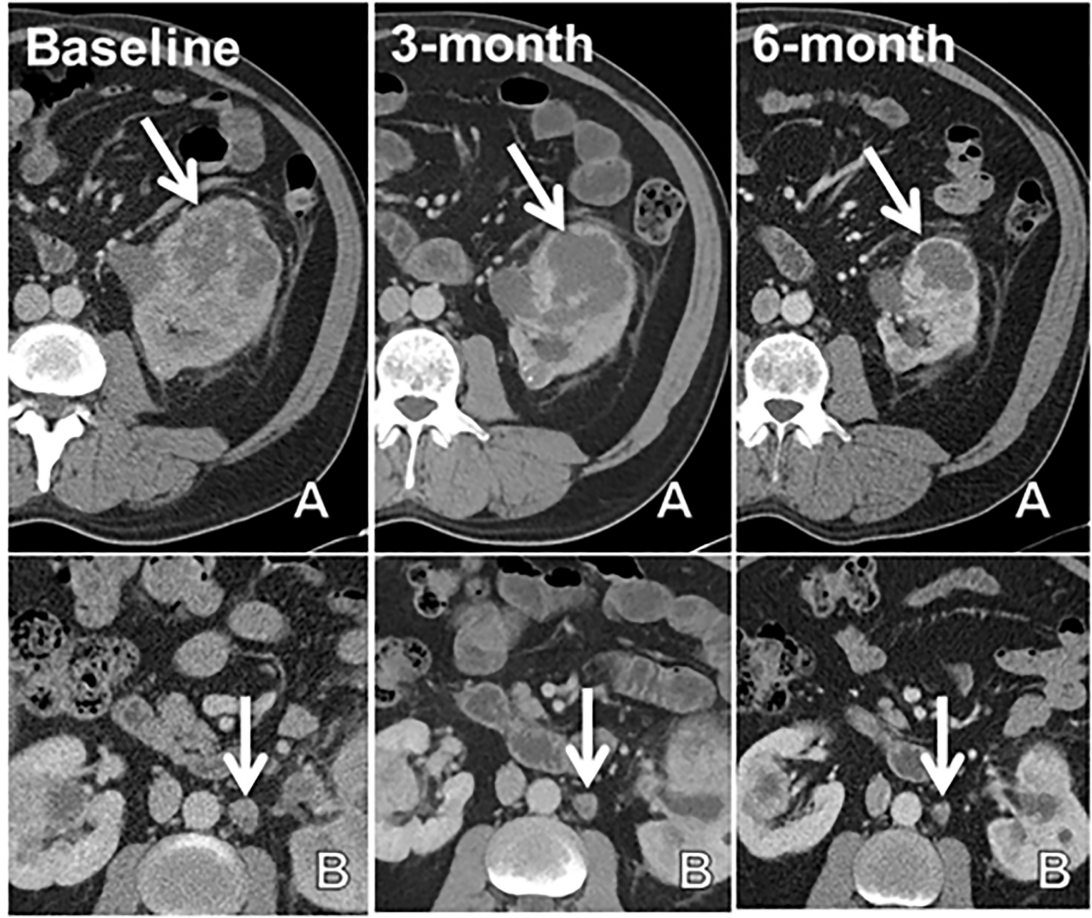

Figure 2. Exceptional response to everolimus seen in a patient with tuberous sclerosis (TSC)-associated RCC (A) The shrinkage seen in the dominant left renal mass; $(B)$ the reduction in size noted in the para-aortic adenopathy at 3- and 6-mo after starting therapy when compared with baseline. Response is sustained at 2-yr follow-up.

and anti PD-1 immunotherapy (Motzer et al. 2014; Choueiri et al. 2015; Motzer et al. 2015). We found two reports in the literature were found on the use of mTOR inhibitors in TSC-associated RCC. The first report was of a 7-yr-old child with TSC bilateral RCC and fibromatosis of the chest (Pressey et al. 2010). To spare a young patient bilateral nephrectomies, he was treated with the mTOR inhibitor sirolimus, and within $6 \mathrm{mo}$, the fibromatosis and RCC responded dramatically. The second interesting paper by Kim et al. (2014) is of a 49-yr-old woman with TSC and metastatic RCC who failed the TKI sunitinib and was subsequently started on everolimus. The patient had a meaningful clinical benefit and continued response to therapy (at least over a year) at the time of publication of the case report. More interestingly, the patient's other TSC manifestations (fibroadenomas, angiomyolipomas, cortical tubers, and SEGAs) were also ameliorated by everolimus, which further underlines the predominant role that mTOR signaling plays in the pathogenesis of TSC (Kim et al. 2014).

Our patient has remained progression-free for $2 \mathrm{yr}$ into therapy so far. This is several-fold longer than the established durations of responses seen with mTOR inhibitors in RCC (Hudes et al. 2007; Motzer et al. 2014). Less activity and shorter progression-free survival (PFS) have been reported with mTOR inhibitors in the second-line setting (Choueiri et al. 2015; Motzer et al. 2015).

In summary, TSC is a genetic disorder that is associated with frequent tumor formation in various organs. Multiple studies, including randomized controlled trials, have shed light on the mTOR pathway as a major player in TSC-associated tumors and showed that mTOR inhibition represents a vital strategy in counteracting these tumors. Although mTOR inhibitors are not routinely used nowadays in the first-line treatment of metastatic RCC, we believe they are highly active in TSC-associated RCC as uninhibited mTOR signaling appears to be the 
COLD SPRING HARBOR Molecular Case Studies
Tuberous sclerosis complex-associated renal cancer
Competing Interest Statement

The authors have declared no competing interest.

Received July 30, 2017; accepted in revised form September 28, 2017. driving phenomenon. In this report, we showed a case of metastatic RCC in a TSC patient who had an exceptional and durable response to everolimus. Based on these findings, everolimus should be considered for treatment of RCC and other tumors associated with TSC. Further studies of somatic mutations in extended responders to mTOR inhibitors will help personalize therapy for these patients (Voss et al. 2014).

\section{METHODS}

\section{Genetic Testing}

Tumor-based genetic testing was obtained through the Foundation Medicine's commercial platform of FoundationONE assay. As per the company's description of the genomic profiling, the FoundationONE is designed to test at the time of patient's testing 315 genes as well as introns of 28 genes involved in rearrangements. The details regarding the coverage, sensitivity, and specificity of the assay are publicly available and well published (https://www. foundationmedicine.com/genomic-testing/foundation-one). The test recently also was approved by the Food and Drug Administration (FDA) as well for certain solid tumors and indications.

\section{ADDITIONAL INFORMATION}

\section{Data Deposition and Access}

The variants were submitted to ClinVar (http://www.ncbi.nlm.nih.gov/clinvar/) and can be found under accession numbers SCV000693713 and SCV000693714. Sequence data were unable to be submitted to publicly available databases because these data were collected by the clinical reference testing institution without patient consent to do so.

\section{Ethics Statement}

The patient provided informed consent for us to publish the case report. The patient's tumorbased genetic testing was done as part of his clinical care and not research. The publication of the findings noted as a case report does not require an IRB approval.

\section{Acknowledgments}

We are deeply indebted to the patient and his family for allowing us to publish his case as a case report.

\section{Author Contributions}

P.M.K. identified and has been taking care of this patient from a management standpoint. S.A. compiled the data into an initial draft. P.M.K. extensively revised the manuscript and suggested further edits. S.A. completed further simultaneous edits. P.M.K. finished the final draft. Both authors approved the final draft for submission to the journal.

\section{REFERENCES}

Au KS, Rodriguez JA, Finch JL, Volcik KA, Roach ES, Delgado MR, Rodriguez E Jr, Northrup H. 1998. Germ-line mutational analysis of the TSC2 gene in 90 tuberous-sclerosis patients. Am J Hum Genet 62: 286-294

Au K-S, Hebert AA, Roach ES, Northrup H. 1999. Complete inactivation of the TSC2 gene leads to formation of hamartomas. Am J Hum Genet 65: 1790-1794. 
Au KS, Williams AT, Roach ES, Batchelor L, Sparagana SP, Delgado MR, Wheless JW, Baumgartner JE, Roa BB, Wilson CM. 2007. Genotype/phenotype correlation in 325 individuals referred for a diagnosis of tuberous sclerosis complex in the United States. Genet Med 9: 88-100.

Bjornsson J, Short MP, Kwiatkowski DJ, Henske E. 1996. Tuberous sclerosis-associated renal cell carcinoma. Clinical, pathological, and genetic features. Am J Pathol 149: 1201-1208.

Carbonara C, Longa L, Grosso E, Borrone C, Garré MG, Brisigotti M, Migone N. 1994. 9 q34 loss of heterozygosity in a tuberous sclerosis astrocytoma suggests a growth suppressor-like activity also for the TSC1 gene. Hum Mol Genet 3: 1829-1832.

Choueiri TK, Escudier B, Powles T, Mainwaring PN, Rini BI, Donskov F, Hammers H, Hutson TE, Lee J-L, Peltola K. 2015. Cabozantinib versus everolimus in advanced renal-cell carcinoma. N Engl J Med 373: 1814-1823.

Curatolo P, Bombardieri R. 2007. Tuberous sclerosis. Handb Clin Neurol 87: 129-151.

El-Hashemite N, Zhang H, Henske EP, Kwiatkowski DJ. 2003. Mutation in TSC2 and activation of mammalian target of rapamycin signalling pathway in renal angiomyolipoma. Lancet 361: 1348-1349.

Franz DN, Belousova E, Sparagana S, Bebin EM, Frost M, Kuperman R, Witt O, Kohrman MH, Flamini JR, Wu JY. 2013. Efficacy and safety of everolimus for subependymal giant cell astrocytomas associated with tuberous sclerosis complex (EXIST-1): a multicentre, randomised, placebo-controlled phase 3 trial. Lancet 381: 125-132.

Henske EP. 2004. The genetic basis of kidney cancer: why is tuberous sclerosis complex often overlooked? Curr Mol Med 4: 825-831.

Hudes G, Carducci M, Tomczak P, Dutcher J, Figlin R, Kapoor A, Staroslawska E, Sosman J, McDermott D, Bodrogi I. 2007. Temsirolimus, interferon $\alpha$, or both for advanced renal-cell carcinoma. N Engl J Med 356: 2271-2281.

Kim HS, Kim ST, Kang SH, Sung DJ, Kim CH, Shin SW, Kim YH, Cho WY, Park KH. 2014. The use of everolimus to target carcinogenic pathways in a patient with renal cell carcinoma and tuberous sclerosis complex: a case report. J Med Case Rep 8: 95.

Kobayashi T, Minowa O, Sugitani Y, Takai S, Mitani H, Kobayashi E, Noda T, Hino O. 2001. A germ-line Tsc1 mutation causes tumor development and embryonic lethality that are similar, but not identical to, those caused by Tsc2 mutation in mice. Proc Natl Acad Sci 98: 8762-8767.

Kwiatkowski DJ, Manning BD. 2014. Molecular basis of giant cells in tuberous sclerosis complex. N Engl J Med 371: 778-780

Kwiatkowski DJ, Whittemore VH, Thiele EA. 2011. Tuberous sclerosis complex: genes, clinical features and therapeutics. Wiley, New York.

Lipworth L, Tarone RE, McLaughlin JK. 2006. The epidemiology of renal cell carcinoma. J Urol 176: 2353-2358.

Motzer RJ, Escudier B, Oudard S, Hutson TE, Porta C, Bracarda S, Grünwald V, Thompson JA, Figlin RA, Hollaender N. 2010. Phase 3 trial of everolimus for metastatic renal cell carcinoma. Cancer 116: 4256-4265.

Motzer RJ, Barrios CH, Kim TM, Falcon S, Cosgriff T, Harker WG, Srimuninnimit V, Pittman K, Sabbatini R, Rha SY. 2014. Phase II randomized trial comparing sequential first-line everolimus and second-line sunitinib versus first-line sunitinib and second-line everolimus in patients with metastatic renal cell carcinoma. J Clin Oncol 32: 2765-2772.

Motzer RJ, Escudier B, McDermott DF, George S, Hammers HJ, Srinivas S, Tykodi SS, Sosman JA, Procopio G, Plimack ER. 2015. Nivolumab versus everolimus in advanced renal-cell carcinoma. N Engl J Med 373: 1803-1813.

Pressey JG, Wright JM, Geller JI, Joseph DB, Pressey CS, Kelly DR. 2010. Sirolimus therapy for fibromatosis and multifocal renal cell carcinoma in a child with tuberous sclerosis complex. Pediatr Blood Cancer 54: 1035-1037.

Rakowski S, Winterkorn E, Paul E, Steele D, Halpern EF, Thiele E. 2006. Renal manifestations of tuberous sclerosis complex: incidence, prognosis, and predictive factors. Kidney Int 70: 1777-1782.

Shepherd CW, Gomez MR, Lie J, Crowson CS. 1991. Causes of death in patients with tuberous sclerosis. In Mayo Clinic Proceedings. Elsevier, New York.

Siegel RL, Miller KD, Jemal A. 2015. Cancer statistics, 2015. CA Cancer J Clin 65: 5-29.

Tee AR, Fingar DC, Manning BD, Kwiatkowski DJ, Cantley LC, Blenis J. 2002. Tuberous sclerosis complex-1 and-2 gene products function together to inhibit mammalian target of rapamycin (mTOR)-mediated downstream signaling. Proc Natl Acad Sci 99: 13571-13576.

Voss MH, Hakimi AA, Pham CG, Brannon AR, Chen YB, Cunha LF, Akin O, Liu H, Takeda S, Scott SN, et al. 2014. Tumor genetic analyses of patients with metastatic renal cell carcinoma and extended benefit from mTOR inhibitor therapy. Clin Cancer Res 20: 1955-1964.

Yang P, Cornejo KM, Sadow PM, Cheng L, Wang M, Xiao Y, Jiang Z, Oliva E, Jozwiak S, Nussbaum RL. 2014. Renal cell carcinoma in tuberous sclerosis complex. Am J Surg Pathol 38: 895-909. 


\section{COLD SPRING HARBOR Molecular Case Studies}

\section{Exceptional response to everolimus in a novel tuberous sclerosis complex-2 mutation-associated metastatic renal-cell carcinoma}

Samer Alsidawi and Pashtoon Murtaza Kasi

Cold Spring Harb Mol Case Stud 2018, 4: a002220

Access the most recent version at doi: $10.1101 /$ mcs.a002220

References This article cites 24 articles, 4 of which can be accessed free at: http://molecularcasestudies.cshlp.org/content/4/2/a002220.full.html\#ref-list-1

License This article is distributed under the terms of the Creative Commons Attribution-NonCommercial License, which permits reuse and redistribution, except for commercial purposes, provided that the original author and source are credited.

Email Alerting Receive free email alerts when new articles cite this article - sign up in the box at the Service top right corner of the article or click here. 